\title{
ga $\mathfrak{a} \mathfrak{a} \mathfrak{l t}$.
}

(Dte in ben Eezt ober bie Anuerfungen bolftanbig ober unboll. ftanblg elngefiodtenen Befege unb Berorbnungen find gier ntht aufgefubrt.)

I. Finleitung.

Gelle

II. Berfafinungitutruabe . . . . . . . . . 55

Titel J. Urt. 1, 2. 2ain Stautógebiete 58

Titel II. Rrt. 3-42. Fon ben Fedten ber Breuken . . . . . . . . . . . 63

Titel III. Rfrt. 43--6y. Lom stönige. 175

Ittel IV. OTt. 60, 61. Bon ben MRtrtfteru 227

Ittel V. Art. 62-85. Bon ben Rammern 240

Tttel VI. Rrt. 86-97. Bon ber ridter:

lidien Bemalt . . . . . . . . . 300

Titel VII. Qrt. 9s. Won ben nidyt zuII

Midterfanb gebörigen Etaat8beamten . . 322

Titel VIII. Ritt. 99--104. Bon ben צ̈inanzen 325

Titel 1X. Qtt. 105. Bon ben Bemteinben,

Areis :, Bezirls: u. Provinzial = Berbänocn 360

Hugenteine Beftimunngest. Firt. 108-111 . 365

übergangsbeftimumungen. Ret. $112-118 . .381$

11I. $\mathfrak{A} \mathfrak{H}$ a gen:

I. Berorbnung megen Bildung ber Crften Stamuter, volu 12. Oltober $1854 . . .386$

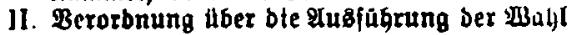
ber Afggeorbneten zur zmelten sammer, vom 30. Dlai 1849 . . . . . . . 398

1W. Sadregifter. . . . . . . . . . 420 
